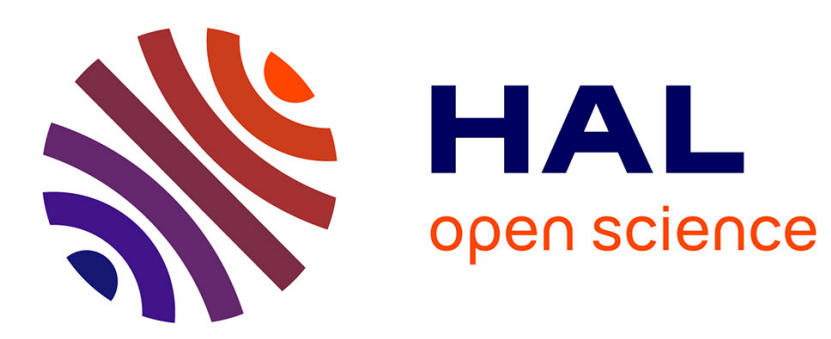

\title{
Immunohistochemical analysis of bone morphological protein signaling pathway in human myometrium
}

Caroline Rouleau, Caroline Rico, Ilona Hapkova, Pascal de Santa Barbara

\section{To cite this version:}

Caroline Rouleau, Caroline Rico, Ilona Hapkova, Pascal de Santa Barbara. Immunohistochemical analysis of bone morphological protein signaling pathway in human myometrium. Experimental and Molecular Pathology, 2012, 10.1016/j.yexmp.2012.04.007 . hal-02543727

\section{HAL Id: hal-02543727 \\ https://hal.umontpellier.fr/hal-02543727}

Submitted on 15 Apr 2020

HAL is a multi-disciplinary open access archive for the deposit and dissemination of scientific research documents, whether they are published or not. The documents may come from teaching and research institutions in France or abroad, or from public or private research centers.
L'archive ouverte pluridisciplinaire HAL, est destinée au dépôt et à la diffusion de documents scientifiques de niveau recherche, publiés ou non, émanant des établissements d'enseignement et de recherche français ou étrangers, des laboratoires publics ou privés. 


\title{
Immunohistochemical analysis of bone morphological protein signaling pathway in human myometrium
}

\author{
Caroline Rouleau ${ }^{\mathrm{a}, \mathrm{b}, *}$, Caroline Rico a, Ilona Hapkova a , Pascal de Santa Barbara ${ }^{\mathrm{a}}$ \\ a INSERM 1046 Unit, "Médecine expérimentale Coeur et muscle", Montpellier University Hospital, 371 avenue du Doyen gaston Giraud, 34295 Montpellier, France \\ ${ }^{\mathrm{b}}$ Institute of Pathology, Lausanne University Hospital, rue du Bugnon 25, 1011 Lausanne, Switzerland
}

\section{A R T I C L E I N F O}

Keywords:

BMP

Human myometrium

Uterine smooth muscle cells

Noggin

P-SMAD1/5

\begin{abstract}
A B S T R A C T
We assessed by immunohistochemistry the expression of the phosphorylated (activated) form of Smad1 and 5 (P-SMAD1/5), of Noggin and of two smooth muscle cell markers ( $\alpha$-SMA and SM22) in a series of human myometrium samples and in a smooth muscle cell line derived from human myometrium (HUt-SMC, PromoCell, USA). Myometrium samples were removed from two cadavers (a fetus at 26 weeks of gestation and a neonate) and from ten non-menopausal women who underwent hysterectomy for adenomyosis and leiomyoma. P-SMAD1/5 expression was never detected in myometrium (both normal and pathological specimens), but only as a nuclear positive staining in glandular and luminal epithelial cells in sections in which also the endometrial mucosa was present. Noggin was strongly expressed especially in myometrium and adenomyosis samples from non-menopausal patients in comparison to the neonatal and fetal myometrium specimens in which muscle cells were less positive. In more than 95\% of HUt-SMCs, $\alpha$-SMA and Desmin were co-expressed, indicating a pure smooth muscle phenotype. When progesterone was added to the culture medium, no P-SMAD1/5 expression was detected, whereas the expression Noggin and SM22, a marker of differentiated smooth muscle cells, increased by 3 fold $(p=0.002)$ and 4.3 fold $(p=0.001)$, respectively $(p=0.002)$.

Our results suggest that, in non-menopausal normal human myometrium, the BMP pathway might be inhibited and that this inhibition might be enhanced by progesterone, which increases the differentiation of smooth muscle cells (SM22 levels). These findings could help in the identification of new mechanisms that regulate uterine motility.
\end{abstract}

\section{Introduction}

The myometrium is the thick muscle layer of the uterine wall. It is located between the inner layer of the uterine mucosa (the endometrium) and the perimetrium and is characterized by two-three badly defined layers of smooth muscle fibers organized in crisscrossing bundles (Robboy et al., 2009). The myometrium derives embryologically from the part of the splanchnic mesoderm that will give rise to a transient common chamber between the urinary and digestive systems (De Santa Barbara et al., 2002). The growth of the myometrium starts during fetal life and gradually continues after birth and during the cyclic changes at puberty. Like the endometrium, the myometrium is very sensitive to sexual hormones (estrogen, progesterone) to which it responds with morphological and functional changes (Robboy et al., 2009). During pregnancy, the myometrium becomes

* Corresponding author at: Institute of pathology, Lausanne University Hospital, rue du Bugnon 25, 1011 Lausanne, Switzerland. Fax: +4121 3147151.

E-mail addresses: r-caroline@hotmail.fr (C. Rouleau), rico.caroline@yahoo.fr

(C. Rico), ilona.hapkova@inserm.fr (I. Hapkova), pascal.de-santa-barbara@inserm.fr (P. de Santa Barbara). considerably thicker due to the presence of high concentrations of estrogens and progesterone. During delivery, the contractile functions of the myometrium allow the expulsion of the fetus and ensure the vasoconstriction of the placental vessels (Teixeira et al., 2008). Uterine leiomyoma, the most common benign gynecologic tumor in women, results from hindered differentiation and deregulated proliferation of smooth muscle cells. Estrogens and progesterone may play an important role in its growth. Uterine adenomyosis, also called endometriosis of the uterus, is a benign condition in which endometrial cells penetrate deep into the uterine myometrium. It commonly affects the posterior wall (posterior side) of the uterus and does not cause cancer.

Bone morphogenetic proteins (BMP) are secreted signaling molecules that belong to the Transforming Growth Factor $\beta$ (TGF $\beta$ ) superfamily. BMP ligands were initially identified as regulators of bone formation, but subsequent studies have demonstrated that they regulate different developmental processes throughout embryogenesis and organogenesis (De Santa Barbara et al., 2003). BMP signaling activity is controlled at many levels, including ligand transcription, ligand-receptor interactions and signal transduction (Faure et al., 2002). This complexity makes more difficult the molecular dissection 
of the pathways and the specific tissue patterning functions that are regulated by these molecules. The intracellular mediators Smad1, 5 and 8 transduce the signals of the BMP2, 4 and 7 ligands and are specifically phosphorylated by the same BMP-type I receptors at the last two serine residues in the carboxy-terminal SSVS motif (Kretzschmar et al., 1997). Anti-phosphorylated Smad1/5/8 (anti-P-SMAD1/5/8) antibodies that specifically detect the phosphorylated (and thus activated) form of Smad1, 5 and 8 have been developed and constitute an important tool to map BMP activation in vertebrates (Faure et al., 2000, 2002; Kretzschmar et al., 1997). Indeed, BMP activation often cannot be predicted based only on the mRNA or protein expression patterns of BMP ligands and/or receptors (Faure et al., 2002; Moniot et al., 2004). For instance, using this antibody we previously described how BMP signaling activity is regulated during visceral smooth muscle cell differentiation. Furthermore, using in vivo approaches, we also showed that aberrant modulation of BMP activity during visceral smooth muscle development hinders the differentiation of these cells and increases their proliferation leading to dedifferentiation (De Santa Barbara et al., 2005). These data highlight that tightly regulated BMP activity is needed to ensure visceral smooth muscle cell differentiation.

In the uterus, studies carried out in animal models indicate that, in the endometrium and myometrium, BMP ligands have a cyclic expression, suggesting that this signaling pathway could be implicated also in the uterine physiology (Erickson et al., 2004). Moreover, during development, the BMP signaling pathway plays a crucial role in the regression of the Müllerian ducts in males by transducing the signals of the anti-Müllerian hormone (Orvis et al., 2008). Finally, during uterine decidualization, the BMP2 and 7 ligands modulate the differentiation of endometrial stromal cells by mediating the intracellular effects of progesterone (PG) (Kodama et al., 2010; Li et al., 2007; Stoikos et al., 2008).

We thus hypothesized that components of the BMP signaling pathway could be involved in myometrium physiology by regulating the effects of steroid hormones (such as PG) as already described for the endometrium. We thus investigated by immunohistochemistry the expression of components of the BMP signaling pathway in human uterine myometrium tissue sections and in a smooth muscle cell line derived from human myometrium.

\section{Material and methods}

\section{Human samples}

Two myometrium samples were removed post-mortem: one from a spontaneously aborted female fetus at 26 weeks of gestation and the other one from a full term female neonate who died shortly after birth. The other samples $(n=16)$ were from ten nonmenopausal women operated at the Arnaud de Villeneuve Hospital University Center of Montpellier (France) and included six healthy myometrium and ten pathological (leiomyoma and adenomyosis) specimens. The samples mirrored the paraffin-embedded specimens used for diagnosis. This research project was approved by the Centre de Protection des Personnes Méditerranée IV.

\section{HUt-SMC lines}

The smooth muscle cell line HUt-SMC (PromoCell, USA), which was derived from human myometrium, was grown at $37^{\circ} \mathrm{C}, 5 \% \mathrm{CO}_{2}$ in $100 \mathrm{~mm}$ dishes (BD Biosciences) in the medium suggested by the vendor (Promocell, USA) with 5\% fetal bovine serum, 0.5\% epidermal growth factor (EGF), basic fibroblast growth factor (BFGF) and Insulin (maintenance medium). To test the effect of sexual hormones on cell differentiation, cells were incubated in Dulbecco's modified Eagle medium (DMEM) in the presence of $10 \%$ fetal bovine serum (proliferation medium), supplemented or not with $10 \mathrm{nM} \beta$-estradiol (E2)
(Sigma) or $10 \mathrm{nM} \mathrm{PG} \mathrm{(Sigma)} \mathrm{for} 48 \mathrm{~h}$. Cell cultures were examined by phase-contrast microscopy (Olympus, Japan).

\section{Immunohistochemistry}

Paraffin-embedded sections ( $3 \mu \mathrm{m}$ thick) were immunostained by using standardized automated procedures and a Dako autostainer (Universal Staining System, Dakocytomation, Trappes, France), as previously described (Rouleau et al., 2009). Antigen retrieval was achieved by heating sections at $98{ }^{\circ} \mathrm{C}$ in $1 \mathrm{mM}$ EDTA (pH 9.0) for $1 \mathrm{~h}$. The BMP pathway was investigated with the rabbit monoclonal anti-P-SMAD1/5 (1:100; clone 41D10, Cell Signaling) antibody that detects phosphorylated SMAD1/5 (Duband et al., 1993) and the goat polyclonal anti-Noggin (1:50; Santa Cruz) antibody that detects the protein that binds to BMP ligands, thus inhibiting their interaction with BMP receptors. Other primary antibodies were a mouse antibody against $\alpha$-SMA (1:400; clone 1A4, Sigma), which is an early marker of smooth muscle cells; a mouse antibody specific for SM22 (1:400; clone 1B8, Abcam), a marker of differentiated smooth muscle cells (Duband et al., 1993), and the mouse monoclonal anti-Desmin (clone cDE-U-10, Sigma) antibody. Immunohistochemistry control experiments were performed by excluding the primary antibody (data not shown).

For immunofluorescence, HUt-SMCs were fixed in $4 \%$ paraformaldehyde and incubated at room temperature with the relevant primary antibodies for $1 \mathrm{~h}$. After washing, cells were incubated with Alexa 488 anti-mouse (Invitrogen, France, 1:2000 dilution) or Alexa 555 antirabbit (Invitrogen, France, 1:2000 dilution) secondary antibodies for $30 \mathrm{~min}$. Cells were rinsed again, mounted in FluorSave reagent (Calbiochem, Germany) and analyzed with a fluorescence microscope (Leica DMLB2, Leica Microsystem, CH) coupled to a camera (Leica DFC 300FX, Leica Microsystem, CH). Levels of Noggin and P-SMAD1/5/8 fluorescence in 5-10 fields, each containing at least 25 cells, were measured and the TRITC fluorescence/Hoechst fluorescence ratio calculated with the Cells and Maps program (http://www.bram.org/ serf/). This program counts the total fluorescence intensity (pixels per cell) in both the TRITC and Hoechst channels and computes the TRITC fluorescence/Hoechst fluorescence ratio to evaluate the relative Noggin and P-SMAD1/5 content per cell.

\section{Statistics}

Statistical analysis was carried out using the Student's t-test when two sets of data were compared. The ANOVA test was used when more than two sets were compared. A p value of less than 0.05 was considered significant.

\section{Results}

Immunodetection of BMP members and smooth muscle markers in normal developing and adult human myometrium

Histological analysis of paraffin-embedded uterine sections revealed from the inside to the outside, respectively, the mucosa and the myometrium. In non-menopausal women, the myometrium was composed of haphazardly organized thick bundles of smooth muscle cells (Fig. 1A). In the neonate sample (Fig. 1B), the myometrium was slightly thicker than in the fetal uterine sample (Fig. 1C).

Immunohistochemical analysis showed a strong and diffuse expression of $\alpha$-SMA, an early marker of smooth muscle cells, in all myometrium samples (Figs. 1D-F). On the other hand, SM22, which is a marker of differentiated smooth muscle cells, was very weakly expressed in fetal myometrium (Fig. 1I) and its expression gradually increased in neonatal myometrium (Fig. $1 \mathrm{H}$ ) to become very strong in the myometrium of non-menopausal women (Fig. 1G). No activity of the BMP signaling pathway was detected in the myometrium by 


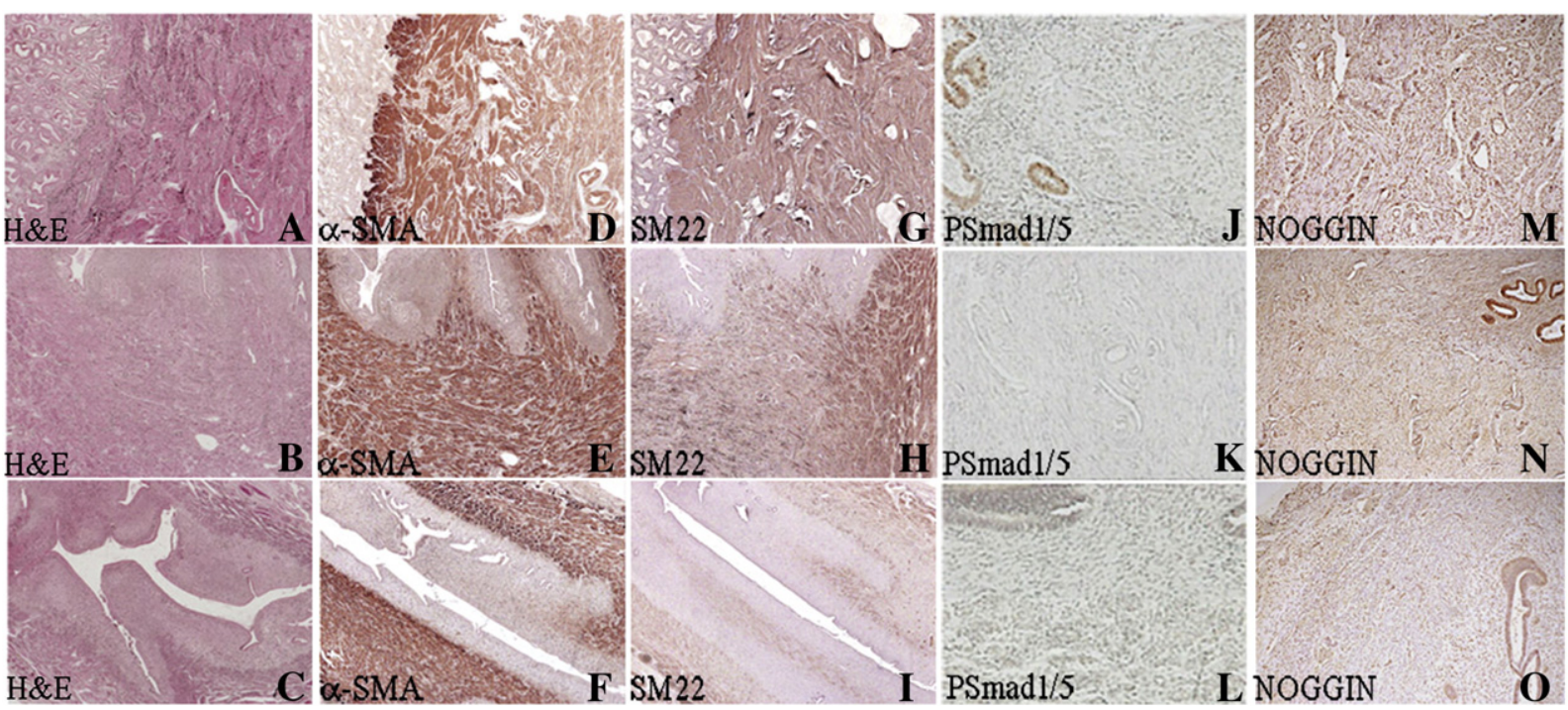

Fig. 1. Detection of smooth muscle cell markers, P-SMAD1/5 and Noggin in normal human myometrium. Hematoxylin-eosin-stained sections (A, B, C), and immunodetection of $\alpha$-SMA (D, E, F), SM22 (G, H, I), P-SMAD1/5 (J, K, L) and Noggin (M, N, O). Normal myometrium tissue sections from a non-menopausal woman (A, D, G, J, M), a female neonate $(\mathrm{B}, \mathrm{E}, \mathrm{H}, \mathrm{K}, \mathrm{N})$ and a female fetus $(\mathrm{C}, \mathrm{F}, \mathrm{I}, \mathrm{L}, \mathrm{O})$. Original magnification $\times 100$

using the anti-P-SMAD1/5 antibody (Figs. 1J, K, L). Conversely, in samples in which the mucosa was present, a nuclear positive staining was observed in glandular and luminal epithelial cells at the luminal surface (Fig. 1J). Finally, Noggin, which inhibits BMP signaling, was strongly expressed particularly in myometrium specimens from non-menopausal patients (Fig. 1M) and slightly more weakly in neonate and fetal myometrium (Figs. 1N, O) in which muscle cells were less differentiated.

Immunodetection of BMP members and smooth muscle markers in human pathological myometrium

In contrast to normal myometrium (Fig. 2A), adenomyosis is characterized by the presence of islets of mucosa (endometrial glands and stroma) within the myometrium (Fig. 2B) and leiomyoma corresponds to a benign proliferation of usually well differentiated smooth muscle cells (Fig. 2C).
In specimens with adenomyosis, $\alpha$-SMA (Fig. 2E) and SM22 (Fig. 2H) were both strongly expressed in smooth muscle fibers, but not in the islets of endometrial mucosa, thus facilitating their identification. On the other hand, in leiomyoma tissue sections, smooth muscle cells were less positive for both markers (Figs. 2F and I). No positive immunostaining could be observed for P-SMAD1/5 in any of the tissue samples (Figs. 2J, K, L). In specimens with adenomyosis, Noggin was expressed in smooth muscle cells surrounding the islets of endometrial mucosa (Fig. $2 \mathrm{~N}$ ) and the expression level was comparable to that of normal non-menopausal myometrium (Fig. 2M). Noggin was also expressed in leiomyomas (Fig. 20), but much less strongly than in the normal myometrium (Fig. 2M).

\section{Effects of estradiol and progesterone on uterine smooth muscle cells}

HUt-SMC cultures were analyzed using both morphological and immunohistochemical approaches. HUt-SMC cultures were characterized

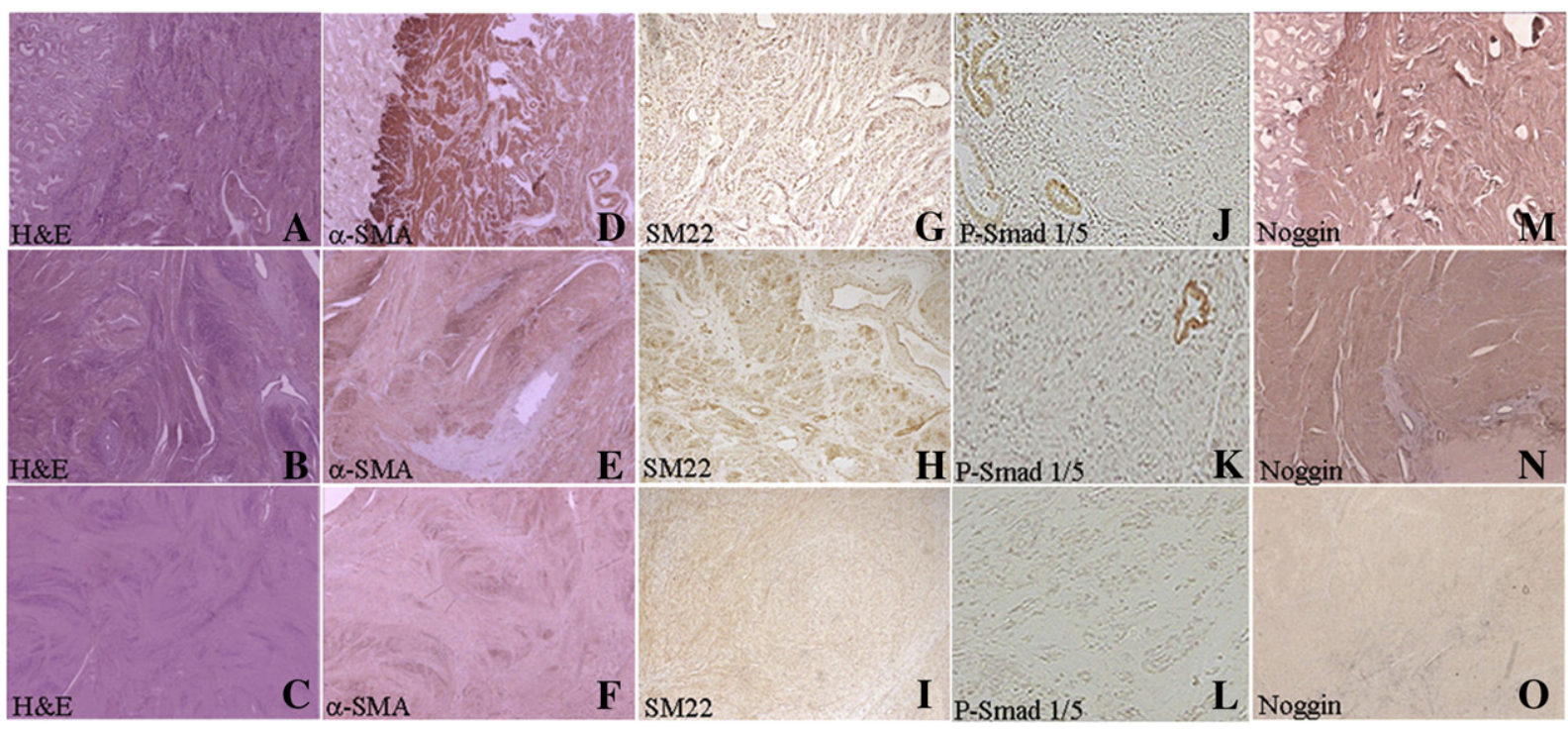

Fig. 2. Detection of smooth muscle cell markers, P-SMAD1/5 and Noggin in myometrium pathological samples. Hematoxylin-eosin-stained sections (A, B, C) and immunodetection of $\alpha$-SMA (D, E, F), SM22 (G, H, I), P-SMAD1/5 (J, K, L) and Noggin (M, N, O). Tissue sections from normal myometrium (A, D, G, J, M), adenomyosis (B, E, H, K, N) and leiomyoma (C, F, I, L, O), Original magnification $\times 100$. 


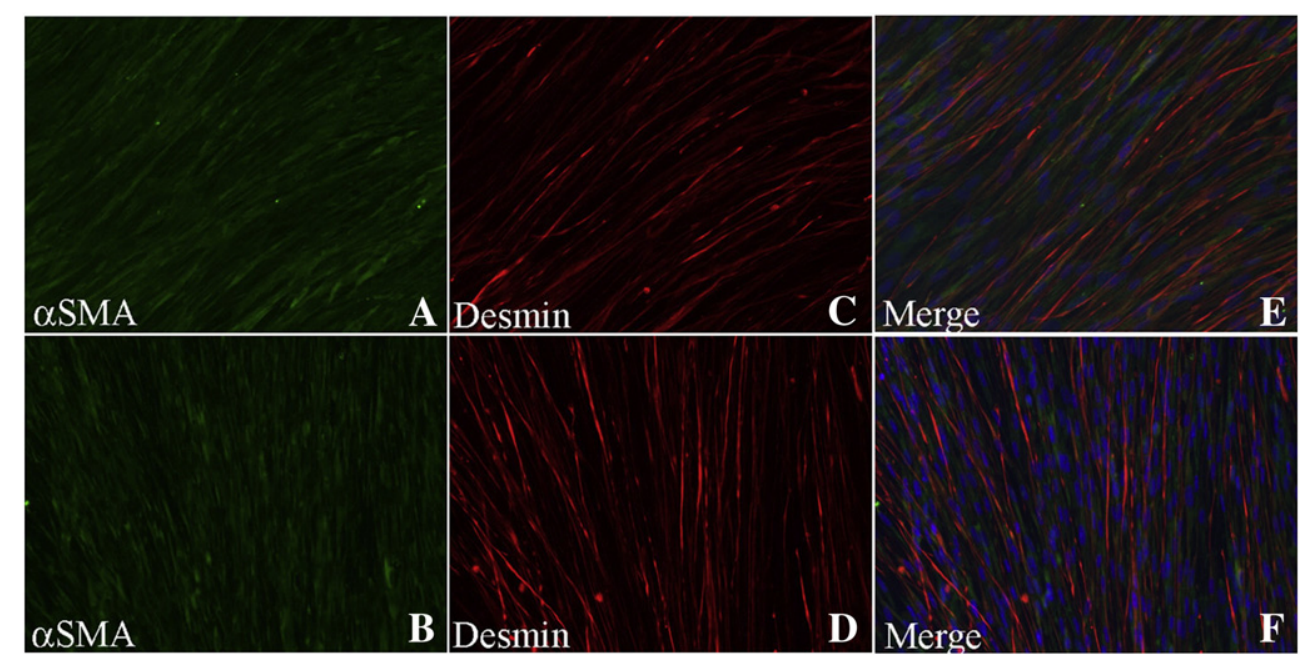

Fig. 3. Immunophenotype of HUt-SMCs. Co-expression of $\alpha$-SMA (A, B) and Desmin (C, D), merged images in (E, F), in HUt-SMCs grown in maintenance medium (5\% fetal bovine serum) (control) (A, C, E) or in proliferation medium (10\% fetal bovine serum) in the presence of $10 \mathrm{nM}$ PG for $48 \mathrm{~h}(\mathrm{~B}, \mathrm{D}, \mathrm{F})$. Original magnification $\times 200$.

by the presence of uniform fusiform spindle-shaped cells, with scant cytoplasm and ovoid nuclei (Fig. 3). More than 95\% of cells expressed both $\alpha$-SMA and Desmin (a mesenchymal marker), indicating a homogenous smooth muscle phenotype (Figs. 3A, C, E). When cells were grown in proliferation medium in the presence or not of E2 or PG for $48 \mathrm{~h}$, a weak P-SMAD1/5 nuclear expression was detected only in control cultures (Fig. 4A) but not in those with E2 or PG (Figs. 4B and C), whereas Noggin (Fig. 4D) increased $(p=0.002)$ by 2.3 fold (E2) and 3 fold (PG) (Figs. 4E and F), as indicated by the quantification of the fluorescence per cell. The levels of $\alpha$-SMA and Desmin were not affected by PG (Figs. 3B, D, F) and E2 (data not shown), whereas SM22 (Fig. 4J) expression increased $(\mathrm{p}=0.001)$ by 2.7 fold (E2) and 4.3 (PG) (Figs. $4 \mathrm{~K}$ and $\mathrm{L}$ ). These findings suggest that the inhibition of BMP activity might be enhanced in the presence of progesterone which also increased SM22 expression.

\section{Discussion}

The aim of this study was to assess the expression and localization of proteins of the BMP signaling pathway in human myometrium. In the absence of data in humans, we decided to use normal uterine specimens at different stages of development (fetus, neonate and non-menopausal adult women) and also samples of very frequent benign myometrial pathologies (adenomyosis and leiomyoma). Expression of P-SMAD1/5 was not detected in any all tested samples, suggesting that SMAD1 and 5 are not phosphorylated in human myometrium. This result needs to be confirmed in a larger sample. Conversely, Noggin, the inhibitor of BMP signaling, was expressed in normal myometrium and it expression showed variations (stronger in non-menopausal than in neonate and fetal myometrium) that were comparable to those observed for SM22. Despite the limited number of studied samples, this result suggests that Noggin expression could be influenced by growth and/or differentiation of smooth muscle fibers in the myometrium. The distribution of smooth muscle markers in the different samples suggests that from the fetal stage, the myometrium contains cells that are determined to become smooth muscle $(\alpha-\mathrm{SMA}+++$, SM $22+)$ and that will progressively differentiate during myometrium growth. Like the endometrium, the myometrium is very sensitive to ovarian steroids (E2, PG) and responds with morphological and functional changes (Teixeira et al.,

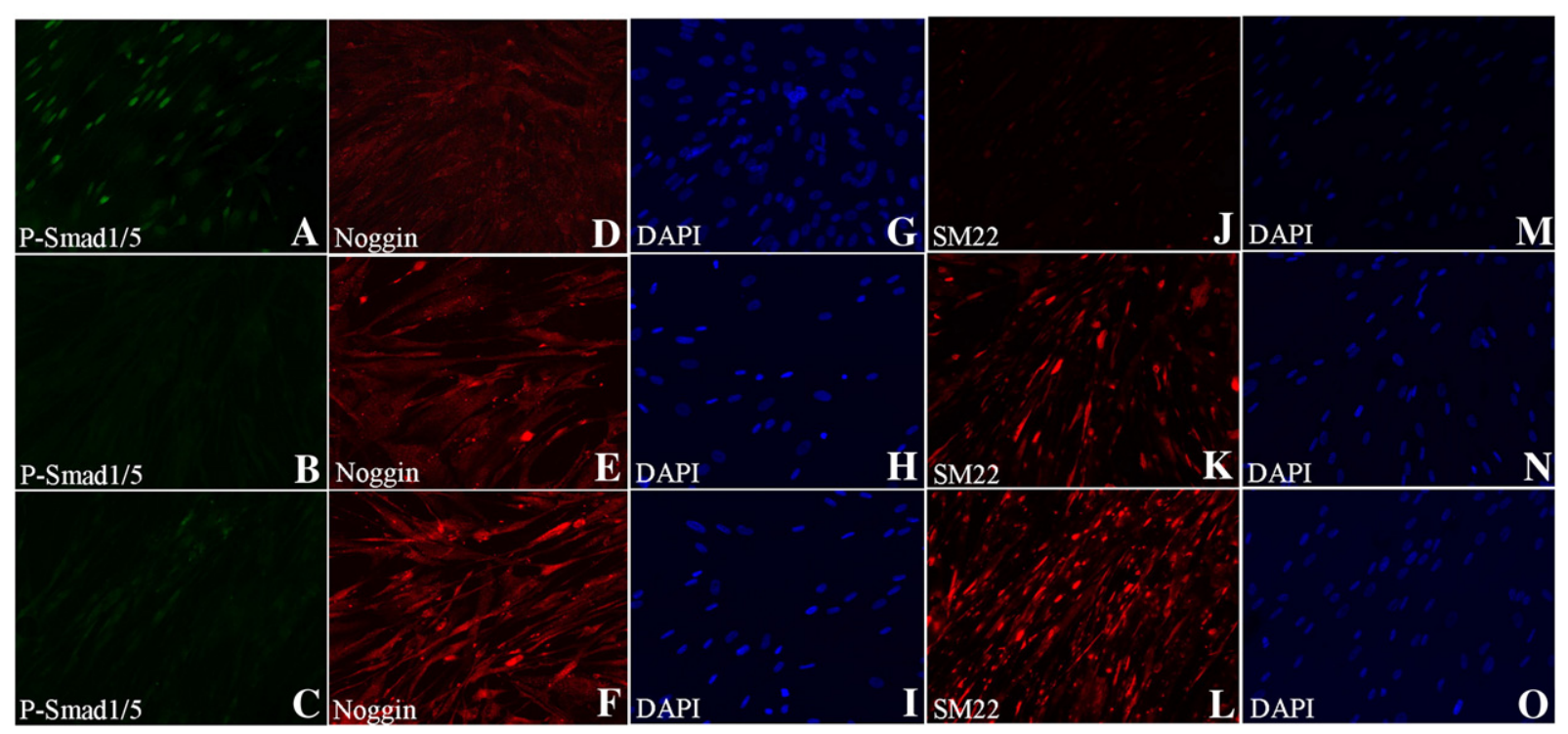

Fig. 4. Detection of P-SMAD1/5, Noggin and smooth muscle cell markers in HUt-SMCs. Immunodetection of P-SMAD1/5 (A, B, C), Noggin (D, E, F) and SM22 (J, K, L). Cells were grown in proliferation medium (10\% fetal bovine serum) without (control cultures) (A, D, G, J, M), or with 10 nM E2 (B, E, H, K, N) or PG (C, F, I, L, O) for 48 h. Dapi (G, H, I, M, N, O). Original magnification $\times 200$. 
2008). As the hormonal status of the non-menopausal patients was not known in all cases and our population was very small, we decided to use HUt-SMCs, which are smooth muscle cells of myometrial origin, to determine whether the expression of proteins of the BMP signaling pathway was influenced by steroid hormones (E2 and PG). HUt-SMCs were characterized by the presence of homogenous smooth muscle cells as indicated by the co-expression of $\alpha$-SMA and Desmin. Following the addition of E2 or PG in the culture medium, only the expression of SM22, a marker of late differentiation (Duband et al., 1993), was increased, whereas the expression of $\alpha$-SMA (early marker) remained unchanged. No significant P-SMAD1/5 expression was detected in cultures. Conversely, Noggin expression was strongly increased following incubation with E2 or PG. These in vitro results are in agreement with the expression data in myometrium tissue sections and suggest that, in normal adult myometrium, [i] the BMP signaling pathway is inhibited and [ii] this inhibition is increased in the presence of PG or E2 that also stimulates the differentiation of smooth muscle cells (as indicated by the increased expression of SM22).

In conclusion, the results of this study are compatible with our hypothesis that BMP signaling molecules might play a role in the physiology of myometrium. Our results should be strengthened by contractility tests of myometrial cells in the presence of steroid hormones and agents that modulate the BMP signaling pathway. As the contractile characteristics of the myometrium are difficult to test outside pregnancy, animal models (pregnant mice) should be set up to better understand the physiology of uterine motricity and possibly to identify new regulatory mechanisms.

\section{Conflict of interest statement}

The authors declare that there are no conflicts of interest.

\section{Contribution to authorship}

Immunohistochemistry assays on tissue samples and cell lines were carried out by CRi and IH, under the supervision of CRo and P de SB. CRo wrote the paper and is the corresponding author. The manuscript was revised by $\mathrm{P}$ de SB.

\section{Funding}

The work was supported by the Région Languedoc-Roussillon (Chercheur d'Avenir), INCA GSO (Projet Emergent), Ligue Contre le Cancer (Comité de l'Aude) and Association Française contre les
Myopathies (AFM) to PDSB. I.H. was supported by a Ministère des Affaires Etrangères fellowship.

\section{Acknowledgments}

We are indebted to Elisabetha Andermacher for editing the manuscript. We thank Anna Thalamo for her help in fluorescence counting and members of INSERM U1046 for helpful discussions.

\section{References}

De Santa Barbara, P., van den Brink, G.R., Roberts, D.., 2002. Molecular etiology of gut malformations and diseases. Am. J. Med. Genet. 115, 221-230.

De Santa Barbara, P., van den Brink, G.R., Roberts, D.J., 2003. Development and differentiation of the intestinal epithelium. Cell. Mol. Life Sci. 60, 1322-1332.

De Santa Barbara, P. Williams, J. Goldstein, A.M., et al, 2005. Bone morphogenetic protein signaling pathway plays multiple roles during gastrointestinal tract development. Dev. Dyn. 234, 312-322.

Duband, J.L., Gimona, M., Scatena, M., et al., 1993. Calponin and SM22 as differentiation markers of smooth muscle spatiotemporal distribution during avian embryonic development. Differentiation 55, 1-11.

Erickson, G.F., Fuqua, L., Shimasaki, S., 2004. Analysis of spatial and temporal expression patterns of bone morphogenetic protein family members in the rat uterus over the estrous cycle. J. Endocrinol. 182, 203-217.

Faure, S., Lee, M.A., Keller, T., et al., 2000. Endogenous pattern of TGFbeta superfamily signaling during early Xenopus development. Development 127, 2917-2931.

Faure, S., Santa, De, Barbara, P., Roberts, D.J., Whitman, M., 2002. Endogenous patterns of BMP signaling during early chick development. Dev. Biol. 244, 44-65.

Kodama, A., Yoshino, O., Osuga, Y., et al., 2010. Progesterone decreases bone morphogenetic protein BMP7 expression and BMP7 inhibits decidualization and proliferation in endometrial stromal cells. Hum. Reprod. 25, 751-756.

Kretzschmar, M., Doody, J., Massaqué, J., 1997. Opposing BMP and EGF signaling pathways converge on the TGF-beta family mediator Smad1. Nature 389, 618-622.

Li, Q., Kannan, A., Wang, W., et al., 2007. Bone morphogenetic protein 2 functions via conserved signaling pathway involving Wnt4 to regulate uterine decidualization in the mouse and the human. J. Biol. Chem. 282, 31725-31732.

Moniot, B., Biau, S., Faure, S., et al., 2004. SOX9 specifies the pyloric sphincter epithelium through mesenchymal-epithelial signals. Development 131, 3795-3804.

Orvis, G.D., Jamin, S.P., Kwan, K.M., et al., 2008. Functional redundancy of TGF-beta family type I receptors and receptor-Smads in mediating anti-Mullerian hormone-induced Mullerian duct regression in the mouse. Biol. Reprod. 78, 994-1001.

Robboy, S.J., Mutter, G.S., Prat, J., et al., 2009. Pathology of the Female Genital Tract. Elsevier (Churchill Livingstone), London.

Rouleau, C., Matecki, S., Kalfa, N., et al., 2009. Activation of MAP Kinase (ERK1/2) in human neonatal colonic enteric nervous system. Neurogastroenterol. Motil. 21, 207-214.

Stoikos, C.J., Harrison, C.A., Salamonsen, L.A., Dimitriadis, E., 2008. A distinct cohort of the TGFbeta superfamily members expressed in human endometrium regulate decidualization. Hum. Reprod. 23, 1447-1456.

Teixeira, J., Rueda, B.R., Pru, J.K., 2008. Uterine stem cells. StemBook [Internet]. Harvard Stem Cell Institute, Cambridge (MA). 